\title{
Is the folk concept of pain polyeidic?
}

Article

Accepted Version

Borg, E., Harrison, R., Stazicker, J. and Salomons, T. (2020) Is the folk concept of pain polyeidic? Mind and Language, 35 (1). pp. 29-47. ISSN 1468-0017 doi:

https://doi.org/10.1111/mila.12227 Available at https://centaur.reading.ac.uk/79706/

It is advisable to refer to the publisher's version if you intend to cite from the work. See Guidance on citing.

To link to this article DOI: http://dx.doi.org/10.1111/mila.12227

Publisher: Wiley

All outputs in CentAUR are protected by Intellectual Property Rights law, including copyright law. Copyright and IPR is retained by the creators or other copyright holders. Terms and conditions for use of this material are defined in the End User Agreement.

\section{$\underline{\text { www.reading.ac.uk/centaur }}$}

\section{CentAUR}

Central Archive at the University of Reading

Reading's research outputs online 


\title{
Is the folk concept of pain polyeidic?*
}

\author{
Revise and resubmit version
}

\section{Abstract}

Philosophers often assume that folk hold pain to be a mental state - to be in pain is to have a certain kind of feeling - and they think this state exhibits the classic Cartesian characteristics of privacy, subjectivity, and incorrigibility. However folk also assign pains (non-brain-based) bodily locations: unlike most other mental states, pains are held to exist in arms, feet, etc. This has led some (e.g. Hill 2005) to talk of the 'paradox of pain', whereby the folk notion of pain is inherently conflicted. Recently, several authors have rejected the paradox view, arguing instead that folk hold a univocal, bodily view (i.e. pains are properties of various body parts, not of minds). This paper presents six objections to the bodily view of the folk concept of pain. We then outline a direction for future research - the 'polyeidic approach' whereby the folk notion of pain is held to encompass various divergent (potentially conflicting) strands and we suggest that certain problems surrounding the treatment and communication of pain might be usefully be viewed through the lens of the polyeidic approach.

Keywords: chronic pain, folk view of pain, paradox of pain, polyeidic concept, bodily view of pain, mental State view of pain, Cartesian mental state.

\section{Introduction}

\footnotetext{
* For helpful comments and discussion, we are grateful to members of the Pain Unit at the University of Reading, to the audience at the 'Pain and Belief' conference (Reading 2018), and those at the $4^{\text {th }}$ Philosophy of Language and Mind European Network conference (Bochum 2017). Thanks also to Adam Bradley and an anonymous reviewer for this journal for helpful comments on an earlier version of the paper, and particular thanks to Murat Aydede for extensive and informative comments and discussion, both in person and in print, which have without doubt greatly improved this paper (and improved our understanding of what philosophy can bring to the study of pain in general).
} 
Pain has a long tradition within philosophy of being considered as a (perhaps the) paradigm mental state. ${ }^{1}$ When we 'turn our gaze inwards', pain, it seems, is just the kind of thing we might find - a private, subjective experience with which the experiencer is directly acquainted. Each person is taken to have privileged, first-person access to their own pain and it is thus something about which they have incorrigible knowledge - though it makes sense to doubt whether others are really in pain, it is often thought that it makes no sense for a subject to doubt of themselves that they are in pain if they feel that they are in pain. Pain states then seem to be classic Cartesian mental states, possessing the characteristic hallmarks of such states: subjectivity, privacy and incorrigibility. Furthermore, philosophers have assumed that this sort of mentalized view captures the ordinary folk notion of pain. Though pain is (typically) caused by bodily damage, pain itself, the man or woman on the Clapham omnibus is held to believe, is a mental state, occurring in minds and heavily dependent on perspective. ${ }^{2}$ However, a moment's reflection on how people ordinarily think and talk about pain shows that the folk view may in fact be somewhat more complex than this model suggests, for folk clearly hold that pains, unlike other paradigm mental states like beliefs, have (non-brain-based) bodily locations. ${ }^{3}$ When someone stubs their toe or cuts their hand the pain is (or at least is said to be) in the toe or in the hand. Recognition of this fact has led some theorists (e.g. Hill 2005) to talk of the 'paradox of pain' - recognising the fact that folk seem happy to allow that pains simultaneously have both mental and physical (bodily) aspects. ${ }^{4}$

\footnotetext{
${ }^{1}$ See, e.g., Block 2005, Kripke 1980, Lewis 1980, Shoemaker 2001, Tye 2005. As a reviewer points out, this way of putting things risks glossing over substantial differences between these different approaches (for instance, while Kripke focuses on the phenomenal aspect of pain, it is much less clear how this figures in the functionalist account of Lewis); for further discussion of what advocates of the Bodily view take to be the 'standard philosophical view' see Sytsma 2010.

${ }^{2}$ See, e.g., Dennett 1978, as discussed in Sytsma 2010.

${ }^{3}$ We will often drop the parentheses in what follows, so unless otherwise stated 'bodily location' should be read as 'bodily location other than the brain'.

${ }^{4}$ For a recent discussion of the paradox, and an embodied solution to it, see Bradley (ms).
} 
Recently, however, a number of authors have used the methods of experimental philosophy to examine philosophical assumptions about the folk conception of pain. They have argued that, contra the traditional philosophical assumption, folk in fact don't think of pains as mental states at all; thus they conclude that there is no 'paradox of pain'. Their evidence for this comes from a range of experiments which seem to demonstrate that ordinary people think of pains as purely bodily phenomena, that they take pains to reside in (nonbrain) body parts and that they reject the idea that pains display the classic hallmarks of Cartesian mental states. Thus Reuter, Phillips and Sytsma 2014: 75 write:

$[\mathrm{M}]$ any philosophers working on pain claim that pain is paradoxical, exhibiting both perceptual and introspective characteristics...[W]e offer a pessimistic take on the putative paradox of pain. Specifically, we attempt to resolve the supposed paradox by undermining the reasons offered for accepting the introspective side of the dualism. ${ }^{5}$

In this paper we want (\$2) to explore the arguments Reuter, Phillips, Sytsma and others give for their pessimism about the introspective side of pain and argue (§3) that there are significant questions to be asked both about the specific methodology deployed in some of their experiments and about the overarching conclusions drawn. ${ }^{6}$ Overall, however, we don't really want to reject the findings canvassed in $\$ 2$ out of hand. For, as we will stress, it is unarguable that the folk conception of pain does treat pains as bodily phenomena, thus it is

\footnotetext{
${ }^{5}$ As an anonymous reviewer points out, this statement of the paradox might seem to differ from the one alluded to above, given that it phrases things in terms of 'perception vs introspection' rather than 'bodily vs mental'. However, we think it is clear from the rest of their work that theorists (like Reuter, Phillips and Sytsma) who champion what we will call 'the Bodily view' do intend to challenge the standard 'paradox of pain' position, which primarily recognises a contrast between bodily and mental conceptions of pain, rather than between modes of access like perception and introspection.

${ }^{6}$ We should note that Reuter 2016 runs an alternative, developmental, argument for the Bodily view. He notes that young children are capable of making genuine pain reports, but argues that psychology has shown that young children (under the age of about 4 years) are incapable of reasoning about mental states and making introspective reports. Thus pain terms, at least for young children, cannot be terms of introspection. We won't pursue this argument further in what follows, but would suggest that the developmental evidence about young children's ability to consider/refer to mental states is much less decisive than Reuter suggests. Thus, in preferential looking versions of false belief tests very young children display behaviour which apparently shows an awareness of, and an ability to reason about, the mental states of others. If this is the case, then we might allow that children, no less than adults, are capable of talking about pain under a mental state conception (for a recent argument in favour of the view that young children do reason about mental states, see Borg 2018).
} 
unsurprising that experimental results can be provided which support this reading. However, we want to argue that (just as those advocating the paradox of pain have claimed) the bodily aspect is just one strand of the folk notion of pain - though sometimes folk think of pains in a strongly bodily way, sometimes they think of pains in a strongly mental way. This will lead us $(\S 4)$ to explore the idea that the ordinary conception of pain as what we will term a 'polyeidic' concept, containing a number of different strands or elements (with the bodily/mental dimension being just one strand amongst others). If this were right, it would come as no surprise that in different contexts different elements of the concept could be activated, enhanced or supressed. Thus in $\S 4$, we take a closer look at what is meant by the claim that pain might be a polyeidic concept, and explore how this claim relates to the wellknown claim that pain is multidimensional. Finally some repercussions of the polyeidic view are examined and we suggest that the polyeidic view may have the potential to improve practical matters surrounding the communication and assessment of pain, particularly between patients and clinicians.

\section{Rejecting the mental state conception of pain}

That philosophers have traditionally assumed that pains are archetypal mental states is clear from the literature. For instance, Kripke 1980: 152 writes: "Pain...is not picked out by one of its accidental properties; rather it is picked out by the property of being pain itself, by its immediate phenomenological quality". While Tye 2005: 100 maintains that "[T]hat pains are necessarily private and necessarily owned is part of our folk conception of pain and it requires explanation. The obvious explanation is that pain is a feeling or an experience of a certain sort". Pains, then, are held to exhibit the classic properties of mental states: they are private (hence the common claim that 'only I can really know my own pain'), they are 
subjective (they belong to the mind and are dependent on a subject's awareness for their existence), and they are incorrigible (there is no possibility of a pain illusion or hallucination - no case where a subject seems to feel pain but no such pain exists). ${ }^{7}$ However, recently a number of theorists (Kim, Phillips, Poth, Reuter, Sienhold, Sytsma) have argued that, on inspection, the folk notion of pain accords none of these properties to pains and thus that philosophers are wrong when they assume that the mentalised model reflects the folk view of pain. ${ }^{8}$ Instead, they argue that folk operate with what we'll label a 'Bodily Conception' of pain whereby pains are properties of bodily states and are located in (non-brain based) body parts rather than in the mind.

Advocates of this approach don't go into great detail about exactly what the Bodily Conception of pain entails, primarily characterising it simply via two claims: (i) pains have non-brain based bodily locations (ii) pains are not in the mind, they are not experiential states. However, while they do suggest that the Bodily view treats pains as associated with bodily damage or disturbance (for instance, Reuter et al 2014: 77 highlight the causal path for awareness of pain which starts with stimulation of nociceptors, while, when introducing the Bodily conception, Sytsma and Reuter 2018: 3 suggest "one might conceive of pains as being qualities of bodily disturbances - that is, as something that can be 'merely instantiated,' such that it might exist without being felt at a given time."), it seems that we shouldn't think of pains as identical to bodily damage on this view. For, when considering the phenomenon of

\footnotetext{
${ }^{7}$ It is something of a moot point whether Kripke's view is committed to incorrigibility, but certainly other philosophers have taken the incorrigibility of pain judgements to be part of the folk view. For instance, Dennett 1978: 226 characterises the following as part of "our stock of pre-theoretical intuitions": "It is a necessary condition of pain that we are incorrigible about pain; i.e., if you believe you are in pain, your belief is true; you are in pain". While Bayne 2012: 52 suggests "On the face of things, it is not implausible to suppose that the introspective judgement that one is not in pain is infallible (that is, could not be false); at the very least, we tend to assume that such judgements are incorrigible (that is, could not be rationally corrected by information derived from other sources). The same might be said, incidentally, of the introspective judgement that one is in pain".

${ }^{8}$ As an anonymous reviewer noted, questions might be raised about whether philosophers (other than Dennett) are really concerned with the folk notion of pain when they suggest that pains be conceived of as mental states. While this is correct, we note that here we are following advocates of the Bodily View who do suggest that this is a common move made by philosophers. Furthermore, it is the folk view of pain that we are explicitly interested in, so even if it turns out that philosophers in general haven't attributed the mental view to folk, it remains a live question exactly how we should understand folk thinking about pain (e.g. as Bodily or Mental).
} 
'referred pains' - where the location of a felt pain diverges from the location of the damage (as when a pain felt in the arm is actually indicative of damage to the heart) - Kim et al 2016: $157-8$ state that the Bodily view is agnostic about whether (i) the pain is really located in the heart but is mis-located by awareness in the arm, or (ii) the pain is really in the arm where it is felt to be. This potential dissociation between the location of the damage and the location of the pain shows that, whatever the specific relationship between pains and injury, they are not identical on the Bodily view. ${ }^{9}$ What we can say, though, is that on the Bodily Conception pains are not experiences caused by the body nor are they representations or perceptions of tissue damage (as philosophers have often treated them), rather they are simply properties of bodily disturbances. ${ }^{10}$ Although awareness of pain is of course a mental state, it is a perception of something external to the mind - the bodily pain state (Reuter et al 2014: $76-7){ }^{11}$

So why exactly, we might now wonder, should we accept that theorists have got the folk so wrong with regards to pain? Why should we believe that the folk do indeed hold a conception of pain that is Bodily? The answer (according to advocates of the view) is that, when we actually go and ask the folk how they think about pain, what we find is that (contrary to philosophical assumptions), folk don't think of pains as necessarily private, necessarily subjective, or necessarily incorrigible. Rather they answer questions in a way that

\footnotetext{
${ }^{9}$ A further reason not to simply equate felt location of pain and bodily damage might be thought to come from phantom limb cases, where a subject will assert that they have, say, a pain in their left arm even though they are missing this limb. As with referred pain, this shows a dissociation between the location of the bodily damage (perhaps to the nerves at the point of amputation) and the felt location of the pain (in the missing limb). However in this case, if the bodily view were to remain agnostic on whether location goes with bodily damage or with felt pain, we would need to allow that pains can be properties of non-bodily locations (i.e. the spatial location where the missing limb is felt to be). If advocates of the bodily view want to avoid this, phantom limb cases will have to be treated as instances where the pain is really where the damage is but this is mis-located by awareness.

${ }^{10}$ For an alternative recent take on the relationship between pains and bodily damage - one which seeks to accommodate the bodily location aspect of pain judgements within a mental state view - see Aydede's 2017b, $2017 \mathrm{c}$, treatment of pain as 'an inverse intentional property'.

${ }^{11}$ Sytsma 2010 draws an analogy to what he takes to be the folk view of colour. He argues that experimental philosophy shows folk think colours exist as part of the world. They hold that colours subsist in external objects (buses and letter-boxes, at least in the UK, are red, regardless of anyone's perception of them) and are not simply brought into being by the mind. And as for colours, Sytsma contends, so for pains.
} 
reveals that they do indeed possess a Bodily Conception of pain. To see this we want now to survey their key experiments.

\section{2.i Against privacy}

Sytsma 2010 experimentally investigated whether subjects thought it was possible for two people to feel the same pain (thus rejecting the putative privacy of pain). In one experiment (Study 5) probing this he asked subjects to consider two different scenarios:

- Henry and Johnny have one of their legs tied together (in order to take part in a threelegged race). While racing, their conjoined legs hit a stone in the grass and both grimace and say 'Ouch'.

- Bobby and Robby are conjoined twins, joined at the torso, though each have their own beliefs and desires. One day when running one of their shared legs hits a stone in the grass and both grimace and say 'ouch'.

After presentation of each scenario participants were asked whether the individuals 'felt one and the same pain' or 'two different pains'. Answers were given on a 7 point scale with 1 being 'clearly same pain', 4 'not sure' and 7 'clearly different pains'. Sytsma found that in the three-legged race scenario participants judged the subjects to experience different pains (mean 5.4), while in the conjoined twin case participants judged that subjects experienced one and the same pain (mean 3.29).

The same result was also found with a more fictional scenario (Study 6) where participants were asked to imagine a scientist who connects the nerve fibres of two different people (both of whom have lost a hand) to one and the same replacement hand (at different times). Here again, where both subjects were biologically connected to the same limb, folk judged that they would both experience the same pain if that limb was injured. Sytsma 2010: 
128 concludes that "it is the number of afflicted appendages, not the number of perceiving brains, that best corresponds with the number of pains reported". This seems to show that the privacy claimed for the folk notion of pain - the idea that nobody but me can experience my pain - is actually a merely contingent characteristic stemming from the fact that typically people don't share body parts and nervous systems. Once this contingent fact is controlled for (as in the above thought experiments) Sytsma argues that ordinary folk seem quite happy to allow that two different people can experience one and the same pain, and thus that pains are not essentially private or something to which the subject alone necessarily has privileged access.

\section{2.ii Against subjectivity: unfelt pains}

We take it that something is subjective, as opposed to objective, if its existence depends on the awareness of a perceiver. Against the alleged subjectivity of the folk conception of pain, Sytsma 2010 explored whether participants would be willing to allow the existence of unfelt pains. He presented participants with a text describing how subjects who have suffered bodily damage can get wrapped up in other things in such a way that they later report that they were not aware of any pain during the period they were concentrating on something else.

Participants were then asked "In such a situation, do you think that the injured person still had the pain and was just not feeling it at the moment? Or, that there was no pain during that period?" Again participants answered on a 7 point scale, with 1 being 'clearly in pain but not feeling it', 4 being 'not sure', and 7 'clearly not in pain'. The mean answer was 3.02, which Sytsma labels as "significantly below the neutral point of 4" (2010: 125), showing that participants were willing to allow that a subject can be in pain yet not be feeling it, that there can be unfelt pains. Thus the folk understanding of pain seems to allow that pains can exist 
unfelt, so there can be an appearance-reality distinction even for pain. Despite common philosophical assumptions to the contrary, then, Sytsma concludes that folk do not think of pains as subjective mental states.

\section{2.iii Against incorrigibility: pain hallucinations}

Reuter et al 2014 presented participants with scenarios where a subject in an atypical situation said that they felt pain. Participants were then asked whether it was possible, in that situation, that the subject was in fact hallucinating the pain - that even though there was a way it felt for the subject (as if they were in pain) this didn't match reality (there was no pain). If pain hallucinations were possible this would reinforce the idea that there is an appearance-reality distinction for pains - how it seems to someone might not be how it is. If participants allow that other features of the situation may warrant the verdict that the subject is not in pain, despite how things appear to the subject themselves, this seems inconsistent with a model which treats subjects as incorrigible about their pains and denies an appearance/reality distinction.

Thus Reuter et al presented participants with the following kind of case:

Jenny is participating in a trial for a new antidepressant being developed by a major drug company. The company suspects that the antidepressant will have some strange side effects. Jenny has been taking the drug twice a day for the past week.

After taking the antidepressant this morning, Jenny is walking down the street when all of a sudden it feels like there is a pain in her ankle. Is it possible that Jenny merely hallucinated the pain?

They summarise responses to this scenario as follows (2014: 86-7): 
We [now] found that almost two-thirds of the participants in the pain condition endorsed the possibility of pain hallucinations (64.5\%). This percentage is significantly higher than the $50.0 \%$ predicted by chance...[O]ur results suggest that contrary to what most philosophers claim, a significant majority of English speakers believe that pain hallucinations are possible. This in turn suggests that they hold a concept of pain that allows for an appearance-reality distinction.

Thus again the conclusion is that, when we actually look at the folk notion properly, we find that philosophers have been too quick to assume that folk think of pain as a mental state, for they do not attribute to pain any of the properties (privacy, subjectivity, incorrigibility) standardly taken as hallmarks of the mental.

However, while these kinds of experiments are clearly fascinating, we think there remain questions to be asked. In the next section we will outline six objections: four to the experimental methodology involved (3.i-3.iv) and two to the overarching structure of the argument developed by advocates of the Bodily view (3.v-vi).

\section{3) Objections to the bodily conception approach}

\section{3.i) Which folk matter?}

There are three points we think should be noted concerning the samples used in Sytsma et al's experiments: first, sample size was often pretty small and often drawn from university students (so not necessarily representative). ${ }^{12}$ Second, for some experiments subjects were recruited through the website 'Philosophicalpersonality.com' which advertises itself as

\footnotetext{
${ }^{12}$ For instance, in the key anti-privacy experiments ( $\$ 2 . i$ above) the samples were 35 for the conjoined twin thought experiments (Study 5, Sytsma 2010: 126) and 57 for the mad scientist (Study 6, Sytsma 2010: 127). We note, however, that objecting to sample size is something of a cheap point, since it can be levelled at such a wide range of experimental work.
} 
'offering a free personality test'. ${ }^{13}$ Again, it might be wondered how representative a sample is achieved through this particular kind of online recruitment. Third, and most significantly, while the experiments run might perhaps target the conception of pain amongst nonphilosophers in general (since, e.g., 'Philosophicalpersonality.com' rules ineligible responses from participants who self-report anything more than a basic level of philosophical training), it is important to note that the Bodily view Sytsma and colleagues end up attributing to the folk puts them in diametric opposition to the most prevalent clinical definition of pain. The highly influential International Association for the Study of Pain (IASP) definition of pain (which we give in full here) states that pain is:

An unpleasant sensory and emotional experience associated with actual or potential tissue damage, or described in terms of such damage.

The accompanying Note adds:

The inability to communicate verbally does not negate the possibility that an individual is experiencing pain and is in need of appropriate pain-relieving treatment. Pain is always subjective. Each individual learns the application of the word through experiences related to injury in early life. Biologists recognize that those stimuli which cause pain are liable to damage tissue. Accordingly, pain is that experience we associate with actual or potential tissue damage. It is unquestionably a sensation in a part or parts of the body, but it is also always unpleasant and therefore also an emotional experience. Experiences which resemble pain but are not unpleasant, e.g., pricking, should not be called pain. Unpleasant abnormal experiences (dysesthesias) may also be pain but are not necessarily so because, subjectively, they may not have the usual sensory qualities of pain. Many people report pain in the absence of tissue damage or any likely pathophysiological cause; usually this happens for psychological

\footnotetext{
${ }^{13}$ http://philosophicalpersonality.com/begin.html
} 
reasons. There is usually no way to distinguish their experience from that due to tissue damage if we take the subjective report. If they regard their experience as pain and if they report it in the same ways as pain caused by tissue damage, it should be accepted as pain. This definition avoids tying pain to the stimulus. Activity induced in the nociceptor and nociceptive pathways by a noxious stimulus is not pain, which is always a psychological state, even though we may well appreciate that pain most often has a proximate physical cause. (IASP Committee on Taxonomy, 2011) ${ }^{14}$

It is clear then that the paradox that Hill locates in folk views of pain is also an explicit part of the standard clinical definition of pain, whereby pain is 'a [subjective] sensation in a body part'. Thus if advocates of the Bodily view are right in claiming that ordinary folk really have a purely bodily conception of pain, this seems to entail that folk and clinical practitioners are currently simply talking past one another when they attempt to talk about pain, since pain practitioners themselves seem overtly committed to the experiential nature of pain. Yet while it seems plausible to think that there are some differences between the notion of pain employed in folk talk and the notion of pain involved in clinical settings, the idea that they are simply entirely different concepts seems highly problematic.

\section{3.ii) Acute pain vs. chronic pain}

Philosophers have historically tended to focus on acute pain, i.e. pains which stem directly from overt tissue damage such as stubbing toes, cutting hands, etc., and this is a trend advocates of the Bodily view continue (it is worth noting that, as far as we can see, all the thought experiments run by these theorists concern acute pain). However it is clear that acute

\footnotetext{
${ }^{14}$ For recent discussion of the IASP definition, see Aydede 2017a.
} 
pain is at best only half the story, for chronic pain is currently endemic in society. ${ }^{15}$ Chronic pain is a long-term condition where patients have on-going pain (or have recurrent bouts of pain) over an extended period, where this may persist beyond the natural period of healing and is often resistant to pharmaceutical interventions. In at least some chronic pain conditions (e.g. Group 1-9 in the IASP Classifications of Chronic Pain, 1994/2002) pain is experienced diffusely around the body rather than being localised to a specific body region. Thus fibromyalgia patients report pain which changes its location across time, moving around the body, or pain which lacks any specific bodily location but is rather experienced diffusely throughout the body. ${ }^{16}$ Prima facie then these chronic pain conditions seem to fit poorly with the Bodily Conception and it is interesting to speculate how patients with these conditions those whose life experiences might unfortunately be thought to equip them with a special kind of expertise about pain - conceptualise pain and the role which bodily location plays in it. If differences in the role of the body in pain were to be found amongst these kinds of groups, there would seem to be two options to accommodate this: either we would have to allow that there is no single folk notion of pain (something Kim et al 2016 lean towards) or that the bodily location element of pain recorded by Sytsma et al is not a necessary or exhaustive feature of the concept itself but a mere typicality feature (that is to say, the people surveyed thought of pain as a bodily feature at least in part because their experience was of localised, acute pain). We'll return to this latter option, whereby bodily location is sometimes appropriate for talk about pain and sometimes not, below (§4).

\footnotetext{
${ }^{15}$ For instance, a recent survey (Fayaz et al, 2016) speaks of the 'silent epidemic' of nearly 28 million UK adults affected by chronic pain, while the TUC has estimated that 4.9 million work days per year are lost in the $\mathrm{UK}$ in relation to back pain alone.

${ }^{16}$ Of course, advocates of the Bodily view may object that these kinds of non-localized or moving pains still cohere with the Bodily view, since they do have bodily locations, albeit vague or transitory ones (thanks to Adam Bradley for stressing this point). However, this pushes on exactly what is required for the Bodily view (see also n.8), for (at least with the case of moving pains) it cannot be the case that the bodily location provides an identifying criterion for the pain. Yet, since it also cannot be experiential properties which individuate the pain on the Bodily view, we might wonder what features are individuating pains on this view. At the very least then, the recognition that some pains are diffusely located and mobile casts doubt on the idea that bodily location plays the central role suggested by advocates of the Bodily conception.
} 


\section{3.iii) How should we ask folk whether they think pain is a mental state?}

The question advocates of the Bodily view want to address is 'do folk think of pains as mental states?'. However we would suggest that this is in fact a pretty tricky question to address directly to the folk and, furthermore, it is quite unclear that the way Sytsma et al choose to pose it really asks the right question. So the way they tend to frame the question is in terms of whether the participant thinks a given pain is 'in the mind' (e.g. Sytsma 2010: 123: "Do you think that the pain you feel when you forcefully stub your toe is in your mind?"; see also Kim et al 2016: 151: “The pain is in Jack's mind, and neither in his left arm nor in his liver"). For a start, since mental states are supposed to be things which lack, or for which it makes little sense to give, a physical location, asking whether pain is in the mind may seem like something of a category mistake. Even for states that are (we take it) unquestionably mental, formulating a question in this way seems odd. It's not obvious what answer folk would give to the question 'Is John's belief that $2+2=4$ in his mind?' or 'Is Samir's desire for a new bike in his mind?', yet unless folk are willing to give robustly positive answers to these kinds of questions, it is left open that a low level of positive response to the question 'Is X's pain in her mind?' is triggered by something about the question rather than something about the concept of pain itself.

Furthermore, we would suggest that a question like 'Is Jack's pain in his mind?' is extremely likely to be heard by ordinary folk as in fact asking whether Jack's pain has a somatic (bodily) cause, or indeed whether he is really in pain or is in some way confabulating or making it up. It is well-attested that patients with chronic pain are often extremely keen to find a discrete somatic cause for their pain and often this has less to do with the idea that finding such a cause will increase the likelihood that their pain can be successfully treated 
and much more to do with the feeling that finding a non-brain-based bodily cause will vindicate their experience, proving to clinical staff that they are not in some way 'shamming'. Yet given the pejorative implicatures associated with the claim that someone's pain is 'in the mind', there is a significant risk that folk resist saying that pain 'is in the mind' either if they can identify a clear somatic cause or if they feel sure the subject really is in pain. This would be the case even if they do in fact think of pain (at least in part) as being a mental, experiential state. To properly explore whether there is a mental component to the folk view of pain, i.e. whether ordinary people think of pains as (at least in part) subjective, experiential states, we think we need to find a much less loaded way of asking the question.

\section{3.iv) Counting pains}

On a related point, we might note that Sytsma et al's way of reporting their findings is perhaps not always quite as objective as it could be. For instance, although Sytsma et al are certainly correct when they report statistically significant findings, the mean scores (across the 7 point scale) were interestingly not far from neutral in many of the cases. Recall that the scale used was a 7-point scale anchored at 1 with 'clearly same pain,' at 4 with 'not sure,' and at 7 with 'clearly different pains'. In the conjoined twin case, the mean answer was 3.29 , below the 'not sure' answer but only by 0.71 , showing, we suspect, that people were pretty unsure about how to categorise this case. In Study 6 (the robotic hand) the mean was 3.42, so only 0.58 below the neutral 'not sure' answer.

Furthermore, consider the results in the first part of Study 5: Henry and Johnny's three-legged race scenario. Here it is interesting to note that the mean was 5.4, a difference from the 'not sure' answer of '4' of 1.4. This does show that people were somewhat more certain in this case that there were two pains than they were in the conjoined twin case that there was only one pain. However a mean of 5.4 is still a long way from the categorical ' 7 ' 
anchored as 'clearly different pains'. Thus in the three-legged race thought experiment where there are two different people with two different legs, both of which get injured at the same time - subjects were still pretty unsure about whether or not there were two different pains. Yet this looks problematic, we think, for the claim that the folk are operating with a Bodily view. For if folk operate with a simple view of pains as properties of bodily parts (standardly, those parts that have suffered some kind of damage), surely folk should feel confident in asserting that in the three-legged race there are clearly two different pains (after all, this is what we would predict given Sytsma's 2010: 128 claim that folk think that it is the number of afflicted appendages that best correlates with the number of reported pains). In fact what the results seem to show is that, even in clear, classic cases of acute pain, folk don't really have very firm views about how pains get individuated (and this uncertainty is compounded in experimental scenarios like Sytsma's 2010 Study 5 and Study 6 where there is no guidance about whether folk are supposed to be counting type or token pains).

We'd suggest then that the nuts and bolts of Sytsma et al's experiments need refining if they are to provide really robust data. Yet, even bracketing these concerns, we also want to argue that the experiments are in principle simply unable to support the conclusion that Sytsma et al want (i.e. that folk hold a Bodily Conception of pain). We argue for this in the next two sections.

\section{3.v) Must all mental states possess Cartesian characteristics?}

In order to show that pain is not thought of as a mental state, Sytsma et al seek to show that folk don't accord pains the properties associated with Cartesian accounts of the mental. That is to say, the folk don't think of pains as private, subjective, and incorrigible. If folk think that it is required for something to be a mental state that it be held to have these properties, this would be a valid move, but the assumption that all mental states are held to be Cartesian 
mental states stands in need of support. From a philosophical point of view, many theorists have questioned whether the Cartesian model is in fact the best or the only way to think about mental states. More relevantly here, the folk themselves seem willing to allow that there are mental states that do not display such properties. For instance, Freudian notions of the unconscious have significant traction in at least some sections of society, yet it is part and parcel of this model of the mind that some thoughts are best (or indeed perhaps only) accessed via third-person investigation (thus folk are often willing to accept claims like 'My therapist discovered that I've always felt jealous of my sister. It was a revelation.'). Thoughts located within the Freudian unconscious are, it seems, judged to be no less mental than consciously accessible ideas, even though the properties of privacy, subjectivity and incorrigibility are rejected for them. If this is right, then clearly an alternative way of reading Sytsma et al's experiments, even were we to accept that they unproblematically go through, would be as showing that folk think that pain is a non-Cartesian mental state (rather than as showing that they don't think pain is a mental state at all). That is to say, even if we accepted all the experimental data of the Bodily theorists, it would still remain to be shown that folk think of pains as Bodily and not as (non-Cartesian) Mental. ${ }^{17}$

\section{3.vi) Can the experiments show the Bodily view correct?}

It seems the overarching structure of Sytsma et al's argument is as follows:

1) Philosophers assume that the folk concept of pain is of a mental state.

2) In a range of philosophical thought experiments, folk respond to probes in a way that shows their concept of pain is of a bodily (rather than a mental) state.

3) Therefore: the folk conception of pain is Bodily.

\footnotetext{
17 This point is recognised in Sytsma and Reuter 2018: 23, where they acknowledge that "The studies we presented...were primarily designed to test the standard [Cartesian] view, not to adjudicate between [the Mental and Bodily conceptions], and the results are consistent with both", and they acknowledge that further empirical work would be needed to adjudicate between these two alternatives.
} 
On the basis of (3) they conclude that philosophers have been wrong in how they characterise the folk view of pain. ${ }^{18}$ However, (3) doesn't follow directly from (2), rather what follows is: $3^{*}$ The folk conception of pain is (at least in part) Bodily.

To derive (3) rather than $\left(3^{*}\right)$ what would be needed is to show that the folk view of pain is exclusively Bodily, i.e. that the Bodily and Mental conceptions are incompatible and that it is not also possible to provoke responses appropriate to a Mental State view from participants. Yet intuition and experimental evidence both suggest that this is not the case, i.e. that it is possible to elicit responses appropriate to a Mental State view from folk. The intuitive point can be seen by reflecting on the fact that philosophers who stressed the experiential aspect of pain didn't seem to be making an obvious mistake - when Kripke suggests that pains are picked out by the particular way they feel this seems intuitively compelling. We know, having experienced pains, that there is a particular way that they feel and that it is this phenomenological profile that makes pains so compelling.

Furthermore, the idea that folk often do think about pains as mental states is reinforced by preliminary results from further experimental work examining folk usage. If you frame your questions in the right way, initial findings suggest that folk do respond to prompts in a way consistent with the claim that they are utilising a Mental State, rather than Bodily, view of pain. So, in recent experimental work, we constructed a series of vignettes designed to reveal any dissociation between the mental/experiential state of pain and states of bodily disturbance or damage (for full experimental details see Harrison et al, manuscript). We constructed eight scenarios, each of which focused on one of the following possibilities:

\footnotetext{
${ }^{18}$ To properly derive this further conclusion from (3) there are two further assumptions that also need to be made (thanks to Murat Aydede for stressing this point): it is necessary to assume (i) that the Bodily and Mental conceptions are incompatible, and (ii) that the folk notion of pain is ultimately coherent. Since we agree with advocates of the Bodily view about (i) we set it aside here. (ii) is more complicated. It is denied by eliminativists (like Dennett or Hardcastle), who argue that the incoherence of the folk notion means that ultimately it should be replaced in an improved, scientific language. While we don't think eliminativism is right, our view on the incoherence question is not fully settled (see $\S 4$ for brief further discussion), but Aydede is right to stress that the argument above requires a background assumption of coherence to go through.
} 
i. $\quad$ Pain without bodily damage. ${ }^{19}$

ii. Bodily damage without pain.

iii. Same bodily damage but not the same pain.

So, for instance, we presented subjects with the following kinds of vignette:

Study 1

Adam and Zed are conjoined twins that are joined at the torso. While they are distinct people, each with their own beliefs and desires, they share the lower half of their body. One day while running through a park they forcefully kick a rock that, unbeknownst to them, was hidden in the grass. Adam grimaces and says 'ouch', Zed doesn't. On examining their shared leg both agree that there is tissue damage (there is a scrape where it hit the stone) but while Adam says it hurts, Zed insists it doesn't. 1) On a scale of 1-7, where '1' is clearly agree and '7' is clearly disagree, how much do you agree with the statement: Adam has pain.

2) On a scale of 1-7, where ' 1 ' is clearly agree and '7' is clearly disagree, how much do you agree with the statement: Zed has pain.

Study 2

\footnotetext{
19 There is a complication here since, as noted in $\S 1$, it is somewhat opaque exactly what the relationship is between pain and bodily damage on the Bodily view. Kim et al 2016 argue that a pain which is felt to be at a bodily site other than the site of tissue damage (i.e. referred pains) still supports the Bodily view, hence the Bodily view must maintain that pain is not equivalent to tissue damage. It is unclear however whether the Bodily view would countenance pains as properties of (non-brain) body parts where there is no bodily damage at all: if I feel a pain in my leg but there is no concomitant damage at any (non-brain) bodily location, does this still count as an instance of the bodily conception of pain simply in virtue of the pain being felt to have a bodily location? If so, pain can be a mind-independent property of a body even if there is no physical cause for that pain (in this way, pains would be properties of body parts not bodily disturbances). Or would this count as an instance of pain hallucination under the current view, whereby the subject seems to feel pain but there is no pain really in existence? We assume the Bodily view endorses the latter position - that some form of bodily injury or disturbance is required for pain to exist, though the location of this damage may differ from the location of the pain - as otherwise we think that the clear blue water between the Bodily and the Mental views risks being lost. However this might ultimately be something advocates of the Bodily view deny.
} 
Maya is an ice skater who takes a bad fall on the ice and injures her wrist. At the time she says it doesn't hurt, even though the damage to her hand is evident to all (it swells and bruises). Later on, looking back on the incident, Maya remarks "It was the darndest thing, although I couldn't use my hand properly it never actually hurt, not when the accident happened, not when they were treating it at the hospital, and not when it was bandaged up. Although I could see the damage, it was never actually painful."

1) On a scale of 1-7, where ' 1 ' is clearly agree and '7' is clearly disagree, how much do you agree with the statement: Maya was aware of pain from this injury.

2) On a scale of 1-7, where ' 1 ' is clearly agree and '7' is clearly disagree, how much do you agree with the statement: Maya had pain from this injury.

For these and other vignettes, initial analysis shows that participants tended to respond in ways consistent with using a Mental State view of pain; i.e. that they thought of pain as a mental, experiential state not as something in the body which subjects might or might not be aware of. ${ }^{20}$ This supports the intuitive idea that, in at least some contexts, people do think of pain as a mental, affective state and not as a bodily one.

To be clear however: although we have argued in this section that there are problems with the experiments run by Sytsma et al and with the conclusion they reach based on these experiments, in fact we think it is unarguable that folk do utilise a Bodily conception of pain (on some occasions). Any situation where the focus is on the bodily damage is likely to be

\footnotetext{
${ }^{20}$ In Study 1, the mean for statement 2 ('Zed has pain') was 5.70, for Study 2, the mean for statement 2 ('Maya had pain from this injury') was 5.79. Both results show that participants generally did not think that bodily injury, in the absence of awareness of pain, sufficed for the existence of pain (apparently showing that participants were adopting a mind-centric, rather than a body-centric, view of pain). Overall, all the results obtained in the pilot study yielded results that were statistically different to the mid-point (4) and that supported the claim that folk were utilising a Mental State view of pain (see Authors ms).
} 
one where a Bodily view of pain comes to the fore. On the other hand, as intuition suggests and as preliminary experimental findings show, there are other contexts - those where the experiential aspects of pain are emphasised, e.g. thought-experiments of the kind to the fore in much traditional work on the philosophy of pain - where a Mental State conception of pain is likely to be operative. Reflection on our thinking about pain then supports not a univocal Bodily view but an approach that accepts that the folk conception of pain is complex. ${ }^{21}$

Assuming this is correct, however, it leaves us with substantial further questions about how we should respond. One possible response would be to claim that this shows the folk notion of pain should be eliminated in favour of some other, more internally consistent notion (Dennett 1978, Hardcastle 1999; see Corns 2016 for an interesting recent discussion of pain eliminativism, though we would not agree with her suggestion that 'scientific eliminativism for pain', i.e. the view that the term 'pain' should be eliminated from scientific discourse, is plausible). Alternatively, we may think that the results show that we need to develop a more nuanced way of modelling the folk concept of pain, one which can accommodate this internal complexity and show how it is that ordinary speakers and thinkers are able to operate so easily with a potentially paradoxical notion (where ordinary folk show little if any awareness of any paradox surrounding their thinking about pain). In closing, then, we want to sketch the outlines of one approach which pursues this latter option.

\section{Is the folk concept of pain polyeidic?}

Psychologists have long recognised that pain is 'multidimensional', where the claim is that pain involves physical, sensory and emotional components, and is affected by psychological, social and contextual factors (where each factor is potentially modulated by, and in turn is able to modulate, the others; e.g. see the biopsychosocial approach of Hadjistavropoulos et al

\footnotetext{
${ }^{21}$ For concerns about univocal philosophical accounts of pain in general, see Corns 2014.
} 
2011). The polyeidic view embraces this claim of multidimensionality but seeks to expand on it in two directions. First, it suggests that the categories recognised in something like the biopsychosocial model of pain are currently too coarse-grained: there are dimensions within the psychological and social realms which it is important to distinguish in order to provide a properly nuanced model of pain thinking (at the very least, as argued for in $\S \S 1-3$, we need to incorporate a mind/body dimension to the concept of pain). Second, the polyeidic view attempts to offer some explanation of how a subject's experience of pain can be modulated by psychological and social factors by pointing to the nature of the folk concept of pain itself. The claim is that the multidimensional modulation identified by psychologists is (in part) made possible by deep facts about the nature of the folk concept of pain. ${ }^{22}$ According to the polyeidic view then:

a) the concept of pain is an amalgam of several distinct dimensions along which beliefs about pains can be ranked.

b) these ideas or dimensions can conflict with one another.

c) subjects hold latent positions on these rankings.

d) rankings are subject to framing effects.

e) positions on these dimensions have direct behavioural effects.

On the polyeidic model, folk come replete with something like an unreflective, personalised theory of pain, whereby they tacitly take a stand across a range of different philosophical questions one could ask about pain (so that the mind/body dichotomy which has been the focus of this paper might turn out to be just one of the dimensions of pain to which people are sensitive). ${ }^{23}$ This individualised view of what pain is can, however, be systematically

\footnotetext{
${ }^{22}$ An earlier example of a view along these lines can be found in Cupples 1992. As the author notes, p.7, "The way in which we define pain influences not only our attitude towards pain but also our approach toward and care for those in pain".

${ }^{23}$ For a view along somewhat similar lines, see Leder 2016. As noted by a reviewer, we should be clear that the arguments of the first part of the paper do not show that the folk notion of pain has several dimensions, only (if
} 
modified by environmental conditions (including things like social setting, upbringing, religious beliefs, etc) or experimental framing effects. In this way, we can have scenarios which privilege the bodily aspects (as in Sytsma et al's vignettes) and scenarios which privilege a mental, experiential conception (as in our vignettes).

Adopting this kind of polyeidic model for the concept of pain makes it clear that there are two pressing questions that we need to settle if we are to clarify how we think and talk about pain: ${ }^{24}$

1. what exactly are the dimensions of the folk concept of pain?

2. how should we model these dimensions?

Providing an adequate answer to either of these questions is unfortunately beyond the scope of the current paper, but we would like to provide an initial sketch of some possible answers here.

So, on the first question: there has been a relatively significant amount of work in both philosophy and psychology which directly or indirectly addresses the question of the dimensions of pain. For instance, the seminal McGill Pain Questionnaire recognises a number of distinct sensory dimensions of pain, including descriptors like burning, throbbing and stabbing as ways of classifying different pains, while the IASP Classification of Chronic Pain 1986/1994 offers an extremely detailed taxonomy of chronic pain conditions, each with its

\footnotetext{
the arguments are successful) that it involves at least one dimension. However we take it that even if, ultimately, the Mental/Bodily dimension were to turn out to be the only one which could be vindicated, still this would suffice to over-turn a range of accounts which construe folk thinking of pain as involving only a single dimension (e.g. the views of Sytsma, Reuter and others that the folk notion of pain is a univocal bodily conception, or the opposing view that folk always think of pain as a mental state) and it would require that the folk concept of pain be modelled as complex rather than atomic (the fundamental claim of the polyeidic approach).

${ }^{24}$ We might hope that answering questions (1) and (2) could help to provide an account of pain with a rather greater degree of normative force than that currently deployed in nursing, according to McCaffery and Beebe 1989: 7, whereby "Pain is whatever the experiencing person says it is, existing whenever the experiencing person says it does".
} 
own set of classifying features. ${ }^{25}$ Furthermore, it is possible to see different philosophical theories of pain as focusing on different dimensions of a more generalised notion of pain. So, for instance, the imperative account of pain (see, e.g. Klein 2015) stresses the motivational aspect of pains (and thus is well-suited to classic acute pains, such as that arising from broken bones, burns, etc, but sits less comfortably with chronic pains and atypical cases like pain asymbolia), while an evaluative approach, such as that in Bain 2013, 2017, stresses the affective aspects of pain - the characteristic unpleasantness of pains - and thus offers a good explanation of their motivational force and their characteristic phenomenological profile, but has less to say about the bodily dimension of pains and their locative properties. ${ }^{26} \mathrm{We}$ suggest then that more work should be done to enumerate exactly what the dimensions of the folk concept of pain are and how they relate to extant philosophical approaches to pain. This will require setting out the criteria by which an aspect of our pain thinking qualifies as a genuine dimension (rather than, say, some purely idiosyncratic difference) and the extent to which any of the associated aspects are held to be necessary or sufficient for pain (as this will help informed decision making in currently controversial cases, such as the debate over whether social pain is really a form of pain at all, or something more like distress). ${ }^{27}$ However, as a first pass, we suggest that the following dimensions are worth further investigation:

\footnotetext{
${ }^{25}$ See also Sternbach's 1968 3-way definition of pain, Szasz's 1975 account of pain as 'sensation plus affect' or Leder's 2016 'experiential paradoxes of pain' view.

${ }^{26}$ Of course, this isn't to vindicate either of these philosophical theories, since, on the polyeidic view, other dimensions of pain thought would also conflict with each of the theories. Rather the point is that, first, we can see why theorists have been led to develop these accounts and, second, why they each seem to possess intuitive appeal, namely because they do each track some genuine dimension of our ordinary thinking about pain.

27 As Aydede has stressed in personal communication, this is obviously a really crucial point, though answering it properly goes beyond the scope of this paper. However we suspect that the criteria will be a question of weighted features rather than an all-or-nothing test; so a putative aspect might be admitted as a genuine dimension of pain thinking if it can be shown to have sufficient generality (i.e. is a pervasive feature of pain thinking across a community rather than a highly individualised aspect) and if it has the right kind of functional role (e.g. people can be shifted along it via relevant thought experiments, it has behavioural consequences, is held by folk to be introspectively relevant, etc).
} 
- mental/bodily dimension: accommodating the fact that folk often think of pains as paradigm mental, experiential states yet also as states located in non-brain based body parts.

- public/private dimension: accommodating the fact that folk often do think of pains as essentially private and yet they also often think of pain as shareable and as having an important social dimension (connecting to Wittgenstein's claim in the Philosophical Investigations that, in the right circumstances, there is just no room for doubting whether another is in pain when they seem to be in pain; see also recent proposals for updating the IASP definition of pain to include a necessary social component, such as Cohen et al 2018).

- conscious/unconscious dimension: accommodating the fact that folk often do think that pain is necessarily felt, yet they will also allow the possibility of unconscious pain (e.g. when subjects are distracted from their pain or when a pain wakes someone up).

- aversive/non-aversive dimension: accommodating the fact that folk typically think of pains as unpleasant and thus aversive, yet will also allow the possibility that pains are not always aversive (as in the case of masochism).

- purposeful/non-purposeful dimension: recognising that folk think of pains as typically useful (i.e. as designed in order to indicate bodily damage) but also as potentially useless (e.g. in chronic pain conditions).

- motivational/non-motivational: accommodating the idea that pains are held to be motivational (they impel us to action to protect, favour or treat the injured part of the body; see Klein 2015), yet folk allow that pain can fail to be motivational (e.g. when considering the case of pain asymbolia). 
- various sensory or affective dimensions (including the degree of intensity, duration, etc): recognising that pains can have different more fine-grained phenomenal properties which allow them to be ranked against one another along these dimensions (e.g. the characteristics used in the McGill Pain Questionnaire).

A separate question, once we have decided exactly what dimensions of pain are needed, concerns how these dimensions are modelled. ${ }^{28}$ There are at least two distinct ways in which the conceptual dimensions could be modelled: on one model, a distinct dimension for each element is introduced (i.e. a dimension for the degree to which a particular pain is viewed as experiential and a dimension for the degree to which a pain is felt to be bodily). This approach would allow us to capture the idea (from Hill 2005) that the folk concept of pain is inherently paradoxical, since at least some of these dimensions (such as the mental/bodily ones) would objectively conflict with one another, and would yield an interesting line of investigation for cognitive therapies for pain management, where part of the role of such interventions might be construed in terms of helping a subject live with the inherently conflicted nature of their pain thinking. Alternatively, however, we might think of these pairs of conflicting properties as the end-points of single dimensions, so that a subject could rank a token pain somewhere on a scale between 'entirely bodily' and 'entirely experiential', with subjects able to shift their rankings on this dimension across time. This kind of approach would accommodate the fact that folk do not seem to feel the pressure of the putative paradoxes of pain, for it would allow that subjects might never actually be irrational in their pain judgements. For although someone might think of pains as essentially experiential at one time and, at a later time, think of them as essentially localised to body parts, they would not

\footnotetext{
${ }^{28}$ To repeat, we recognise that the claim that pain is multidimensional is far from novel: as noted, it is wellestablished in psychology and several recent works in the philosophy of pain have also called for complex accounts of pain (e.g. Corns 2014). However, we suggest that this question of what a complex account might look like in practice hasn't received enough attention. The polyeidic view is thus an attempt to begin to address this lacuna.
} 
be ascribing these properties to pains at one and the same time. ${ }^{29}$ Prima facie we think that this second, single-scale view of the dimensions may be preferable, but further work is clearly needed to explore exactly what the difference in models amounts to (e.g. how might we go about experimentally investigating them?). Secondly, although the polyeidic view has been presented in its strongest form here (i.e. as positing conceptual dimensions for the folk notion of pain), less metaphysically demanding versions of the approach would also be possible (and might ultimately be found more plausible) whereby the dimensions identified constitute not part of the concept of pain itself but rather part of the contextual setting of any pain judgement (akin to placing the dimensions in the pragmatics of pain thinking rather than in the semantics of the folk concept of pain itself). Further philosophical modelling is needed to clarify the best way to conceive of conceptual dimensions (e.g. via a Wittgensteinian family resemblance account, or prototype theory, or via some form of conceptual space approach (as in Gärdenfors 2000).

While the specific answers we ultimately want to give to questions (1) and (2) clearly remain to be settled, we want to close by suggesting that there may be good reasons for wanting to a pursue a polyeidic approach per se: since, on the one hand, it would help to illuminate other theoretical issues and, on the other, it could bring with it practical advances in how we communicate, assess and treat (particularly chronic) pain.

On the first point: questions about the relationship between pain and bodily or brain states will, on the polyeidic approach, admit of complex answers. For instance, asking 'is pain reducible to brain states?' is a question which might admit of distinct answers (at least given the current state of brain research). For while thought of along one of its dimensions (i.e. with an emphasis on bodily aspects) pain might be more easily reducible to talk of tissue

\footnotetext{
${ }^{29}$ To return to the question of whether the polyeidic view is committed to maintaining that the folk conception of pain is paradoxical (see n.17): this version of the view would seem to allow that it was not, since no experience of pain would ever be conceptualised as, e.g., both entirely mental or entirely bodily at one and the same time.
} 
damage or nociceptive activity, considered along other (i.e. experiential or affective) dimensions the concept might well be more resistant to such reductions. As Coghill 2005: 304 writes: "As a sensory and emotional experience, pain is uniquely private and extremely difficult to appreciate from a third-person perspective. Integrating first-person methodologies into the study of populations of subjects is absolutely essential for relating the complex, multiple dimensions of the experience of pain to their underlying neural mechanisms".

On the second point: adopting a polyeidic model of pain could be helpful in ameliorating well-known problems surrounding the communication of pain, particularly between patients and clinicians. Thus for instance patients (particularly those suffering chronic pain) often report that they have trouble communicating their pain to others and that their experiences are not well captured by standard assessment techniques, while clinicians often report finding patients with intractable pain - those who have exhausted the usual clinical routes for investigating and treating somatic causes for their pain - both problematic and frustrating (Levinson et al 1993, Matthias et al 2010, Upshur et al 2010, Hadjistavropoulos et al 2011). The hypothesis to be explored then is that one cause of this dual difficulty lies in background differences in the weightings both parties give to different aspects of the concept of pain, with clinicians (tacitly) weighting physical, bodily aspects more highly, while patients focus on the experiential and affective dimensions. Though both patients and clinicians share a common concept of pain (given by the dimensions), the fact that they can occupy very different places on these dimensions may impede proper communication. One way to improve the experience of treatment, for all parties, then might be to make explicit the constituents of our polyeidic concept of pain, to clarify where individuals stand on these dimensions and to explore which contexts promote which elements of the concept. In this way we might try to bring patients' and clinicians' conceptions of pain more into line with one another, improving communication and ensuring patient pain is seen, 
in these most difficult cases, as a property of a whole person rather than as a mere symptom of some discrete underlying bio-mechanical cause. ${ }^{30}$ Finally, it is well-known that cognitiveor expectation-based treatments (such as CBT, ACT, placebo, mindfulness training) can be effective in treating pain. However, how a subject conceptualizes their pain must, it seems play an intervening role in any such top-down modulation of pain experience. Thus a better understanding of how the folk concept of pain is structured might hold out the promise of improved expectation-based treatments. Theorizing about the articulations internal to our ordinary folk concept of pain might then, have significant clinical repercussions.

\section{Conclusion}

We suggested that there are a number of problems with the experiments used by advocates of the Bodily view: their sample sizes are small and potentially skewed in certain ways (for instance, they continue an unwarranted tradition in philosophy of concentrating on acute pain at the expense of chronic pain). Furthermore, if the question to be examined is 'do folk think pains are mental states?', we need to find a way to ask this question of the folk which doesn't bring with it the pejorative implicatures associated with simply asking if a given pain is 'in the mind'. However, the main challenge of this paper to the Bodily view is that, even were the experimental results to be accepted without question, they are in fact insufficient to establish the desired conclusion (namely that the folk conception of pain is exclusively Bodily). For the experimental results could instead show either that (i) we should reject Cartesian properties as necessary for mental states and/or (ii) we should accept that the folk view of pain is partially Bodily. In this paper we have primarily argued for (ii), suggesting

\footnotetext{
${ }^{30}$ Within pain clinics in the NHS patients are likely to be offered a range of non-pharmaceutical interventions to help them to live with chronic pain. So, for instance, many clinics run courses on mindfulness and ways to accept and live lives of value with pain. In initial work with patients in pain support networks, we found a range of opinions on these treatments, with some reporting them to be very helpful and others suggesting they did not help at all. It is interesting to speculate on whether limning a person's tacit views on pain could act as any kind of predictor concerning outcomes from these non-pharmaceutical interventions and, if so, whether it might be possible to help patients to think about their pain in different ways prior to taking these courses.
} 
that an approach which embraces apparently opposing aspects of the folk view of pain deserves much fuller exploration. Though it is commonplace to talk of pain as multidimensional, we suggest that this is a term which really needs to be much better understood if we are to make progress in understanding beliefs about pain. We have thus suggested one way to make this multidimensionality more concrete (via what we have termed the polyeidic approach), whereby the folk concept of pain itself is understood as complex. On this view, the folk concept of pain is an amalgam of many different dimensions, along which beliefs about pain can be ranked. What this way of thinking about pain makes clear, then, is that we need a much more concrete answer as to exactly what the dimensions of pain are and, following on from this, how we model pain as complex concept. We reject the approach proposed by Sytsma et al, then, not because we think they are wrong to suggest that folk think of pains as Bodily, but because they assume that the folk view of pain is univocal. On the contrary, we have tried to suggest, the folk view may be better modelled as polyeidic.

\section{Bibliography}

Authors. Manuscript. Folk (sometimes) think of pain as a mental state.

Aydede, M. 2005. Introduction: A critical and quasi-historical essay on theories of pain. In Pain: New Essays on Its Nature and the Methodology of Its Study, ed. M. Aydede.

Cambridge, Massachusetts: MIT Press.

Aydede, M. 2017a. Defending the IASP definition of pain. The Monist 4: 439-464

Aydede, M. 2017b. Pain: perception or introspection? In The Routledge Handbook of the Philosophy of Pain, ed. J. Corns. Routledge. 221-232.

Aydede, M. 2017c. Is the experience of pain transparent? Introspecting phenomenal qualities. Synthese. https://doi.org/10.1007/s11229-017-1528-3 
Bain, D. 2013. What makes pains unpleasant? Philosophical Studies 166: 69-89

Bain, D. 2017. Why take painkillers? Nous. Online first. DOI 10.1111/nous.12228

Bayne, T. 2012. How to read minds. In I Know What You're Thinking: Brain Imaging and Mental Privacy, eds S. Richmond, G. Rees, \& S. Edwards. Oxford: OUP.

Block, N. 2005. Bodily sensations as an obstacle for representationalism. In Pain: New essays on its nature and the methodology of its study, ed. M. Aydede. Cambridge, Mass. MIT Press. 137-142.

Borg, E. 2018. On deflationary accounts of human action understanding. Review of Philosophy and Psychology. Online first: https://link.springer.com/article/10.1007/s13164018-0386-3.

Bradley, A. Manuscript. The paradox of pain.

Coghill, R. 2005. Making private experience public. In Pain: New essays on its nature and the methodology of its study, ed. M. Aydede. Cambridge, Mass. MIT Press. 299-306.

Coghill, R., McHaffie, J., Yen, Y. 2003. Neural correlates of interindividual differences in the subjective experience of pain. Proceedings of the National Academy of Science USA 100: $8538-8542$.

Cohen, M., Quintner, J., van Rysewyk, S. 2018. Reconsidering the International Association for the Study of Pain definition of pain. Pain Reports 3: p e634.

Corns, J. 2014. The inadequacy of unitary characterizations of pain. Philosophical Studies 169: 355-378.

Corns, J. 2016. Pain eliminativism: scientific and traditional. Synthese 193: 2949-2971.

Cupples, S., 1992: Pain as a hurtful experience: A philosophical analysis and implications for nursing care, Nursing Forum 27: 5-11.

Dennett, D. 1978. Why you can't make a computer that feels pain. Synthese 38: 415-456.

Reprinted in his Brainstorms, page references to there. 
Fayez, A., Croft, P., Langford, R., Donaldson, L., Jones, G. 2016. Prevalence of chronic pain in the UK: a systematic review and meta-analysis of the population studies. British Medical Journal Open 6: e010364.

Gärdenfors, P. 2000. Conceptual spaces: The geometry of thought. Cambridge, MA: MIT Press.

Hardcastle, V. 1999. The myth of pain. Cambridge, Mass.: MIT Press.

Hadjistavropoulous et al...

Hill, C. 2005. Ow! The paradox of pain. In Pain: New Essays on Its Nature and the Methodology of Its Study, ed. M. Aydede. Cambridge, Mass. MIT Press. PAGES

Kim, H., Poth, N., Reuter K., Sytsma, J. 2016. Where is your pain? A cross-cultural comparison of pain in Americans and South Koreans. Studia Philosophica Estonica 9: 136169.

Klein, C. 2015. What the Body Commands. MIT Press.

Kripke, S. 1980. Naming and Necessity. Cambridge, MA: Harvard University Press

Leder, D. 2016. The experiential paradoxes of pain. Journal of Medicine and Philosophy 41: 444-60.

Levinson, W, Stiles W., Inui T., Engle R. 1993. Physician frustration in communicating with patients. Med Care 31: 285-95

Lewis, D. 1980. Mad pain and Martian pain. In his Philosophical Papers, Volume 1: 216222.

Matthias, M., Parpart A., Nyland K., Huffman M., Stubbs D., Sargent C., Bair M. 2010. The patient-provider relationship in chronic pain case: providers' perspectives. Pain Med 11: 1688-97.

McCaffery, M. \& Beebe, A. 1989. Pain: clinical manual for nursing practice. St. Louis: Mosby. 
Merskey, H., Bogduk, N. 1994. Classification of chronic pain : descriptions of chronic pain syndromes and definitions of pain terms. $2^{\text {nd }}$ Edition. IASP Press.

Resnik, D. 2000 Pain as a folk psychological concept: a clinical perspective. Brain and Mind 1: 193-207.

Reuter, K. 2011. Distinguishing the appearance from the reality of pain. Journal of Consciousness Studies 18: 94-109.

Reuter, K. 2017. The developmental challenge to the paradox of pain. Erkenntnis 82: 265-83

Reuter, K. Phillips, D, Sytsma, J. 2014. Hallucinating pain. In Advances in Experimental Philosophy of Mind, ed. J. Sytsma. Bloomsbury Press. 75-99.

Reuter, K., Sienhold, M., Sytsma, J. 2018. Putting pain in its proper place. Analysis. Online First: https://doi.org/10.1093/analys/any030

Shoemaker, S. 2001. Introspection and phenomenal character. Philosophical Topics 28: 247273.

Sternbach, R. 1968. Pain: a psychophysiological analysis. New York: Academic Press.

Sytsma, J. 2010. Dennett's theory of the folk theory of consciousness. Journal of Consciousness Studies 17: 107-130.

Sytsma, J., Reuter, K. 2018. Unfelt pains. Synthese. Online First: https://doi.org/10.1007/s11229-018-1770-3

Szasz, T. 1975. Pain and Pleasure: a study of bodily feelings. New York: Basic Books. Tye, M. 2005. Another look at representationalism about pain. In Pain: New Papers on its Nature and the Methodology of its Study, ed. M. Aydede, Cambridge, MA: MIT Press.

\section{PAGES}

Upshur, C., Bacigalupe G., Luckmann R. 2010. “They don't want anything to do with you”: patient views of primary care management of chronic pain. Pain Med 11: 1791-8. 
